\title{
Experential Marketing dan Customer Relationship Management Dalam Mempengaruhi Loyalitas Pengguna Jasa Resort Pada Masa Pandemi
}

\author{
Ahmad Yani*1, Miftahul Munir ${ }^{2}$ \\ 1,2Program Studi Manajemen \\ Universitas Islam Kadiri \\ Kediri, Indonesia
}

\section{e-mail: ahmadyani@uniska-kediri.ac,id¹,$\underline{\text { miftahulmunir@uniska-kediri.ac.id }{ }^{2}}$}

\section{Article history Submission: 11 September 2021 \\ Accepted : \\ 24 Desemper 2021 \\ Available online: 25 Desember 2021}

Pengutipan:

Yani,A. \& Munir. M. (2021).

Experential Marketing Dan Customer

Relationship Management Dalam

Mempengaruhi Loyalitas

Pengguna Jasa

Resort Pada

Masa Pandemi.

Jurnal Pendidikan

Ekonomi

Undiksha, 13 (2),

428-437

http://dx.doi.or

$\mathrm{g} / 10.23887 / j \mathrm{jpe}$ .v13i2.39326

\begin{abstract}
Abstrak
Penelitian ini menjelaskan mengenai problematika pengaruh experiential marketing dan customer relationship management terhadap loyalitas pengguna jasa restoran di masa pandemi covid 19 yang mengindikasikan adanya penurunan jumlah customer. Sampel dalam penelitian ini adalah pengguna jasa damarmas resort sebanyak 89 orang dalam kurun waktu 6 bulan penelitian. Mengguunakan teknik aksidental sampling. Pengumpulan data dengan menggunakan kuisioner melalui uji instrument validitas dan reliabilitas, menggunakan teknik analisis regresi linear berganda dan uji hipotesis. Hasil penelitian yang telah dilakukan menunjukkan adanya indikasi pengaruh antara experiential marketing dan customer Relationship Management berpengaruh secara parsial positif dan signifikan terhadap loyalitas pengguna jasa. Secara simultan experiential marketing dan customer Relationship Management berpengaruh positif dan signifikan terhadap loyaltas pengguna jasa di Damarmas Resort Kediri.
\end{abstract}

Kata Kunci: Pengalaman; CRM; Loyalitas

This study explains the problematic influence of experiential marketing and customer relationship management on the loyalty of restaurant service users during the COVID-19 pandemic which indicates a decrease in the number of customers. The sample in this study were 89 customers of damarmas resort within 6 months of the study. Using accidental sampling technique. Collecting data using questionnaires through instrument validity and reliability tests, using multiple linear regression analysis techniques and hypothesis testing. The results of the research that have been carried out indicate an indication of the influence between experiential marketing and customer Relationship Management partially positive and significant effect on service user loyalty. Simultaneously experiential marketing and customer Relationship Management have a positive and significant effect on the loyalty of service users at Damarmas Resort Kediri.

Keywords : Experience; Customer Relationship Management; Loyality 


\section{PENDAHULUAN}

Banyaknya pembangunan resort menumbuhkan persaingan bisnis yang ketat dan menarik minat calon pengguna jasa untuk memilih jasa yang terbaik sehingga manajemen sebuah jasa penginapan perlu melakukan suatu rencana pemasaran yang tertuju pada sasaran yang tepat. Dimasa pandemi seperti sekarang experiential marketing yang baik akan mampu membangun pengalaman yang tidak terlupakan bagi pelanggan. $\mathrm{Hal}$ ini berdasarkan penelitian Soliha et al. (2021) bahwa experiential marketing didesain untuk bisa menciptakan pengalaman layanan yang tidak terlupakan, konsep experiential marketing adalah sentuhan baik secara fisik maupun psikologis yang bisa memberikan kenyamanan bagi pelanggan terhadap layanan yang di dapatkan pelanggan selama berinteraksi dengan perusahaan. Selain itu, menurut Kotler \& Keller (2016) faktor Customer Relationship Management (CRM) juga menjadi salah satu pilihan strategi pemasaran yang diterapkan pengelola jasa dalam mengenali dan menjalin hubungan baik dengan pengguna jasa tersebut. Menurut Chang (2021) Adanya CRM dapat menjalin hubungan atau relasi yang lebih kuat di antara perusahaan dan pelanggannya, dan pada gilirannya sedikit demi sedikit kepuasan pelanggan dapat tercapai. Persaingan bisnis, perusahaan harus dapat menciptakan kepuasan untuk para tamu yang menginap dengan memberkan suatu pelayanan yang ramah dan cepat namun juga berkualitas . Hasil penelitian dari Agustin et al., (2019) menjelaskan CRM harus dilakukan karena jika pengguna jasa tidak puas akan beralih ke pesaing dan akan menyebabakan penurunan penjualan. Sehingga, apabila kepuasan pengguna jasa ini dapat tercipta maka selanjutnya diharapkan adanya loyalitas pengguna jasa yang dinilai sangat menentukan kelangsungan hidup dari suatu perusahaan.

Damarmas resort Kediri adalah salah satu hotel dan restoran terbaik di Kabupaten kediri. Strategi pemasaran melalui experiential marketing dan customer relationship management (CRM) bertujuan sebagai sarana yang tepat untuk menciptakan nilai kepuasan pada diri pengguna jasa terhadap pelayanan disebuah bidang jasa yang diberikan oleh pihak hotel yang nantinya diharapkan akan dapat tercipta loyalitas pengguna jasa.

$$
\text { Experiential marketing adalah }
$$

pendekatan pemasaran yang melibatkan emosi dan perasaan konsumen dengan menciptakan pengalaman-pengalaman positif sehingga konsumen melakukan keputusan pembelian dan fanatik terhadap suatu produk (Smith \& Hanover, 2016). Menurut Batat (2019) experiential marketing adalah suatu cara untuk membuat pengguna jasa mendapatkan pengalaman melalui panca indera (sense), menciptakan pengalaman afektif (feel), menciptakan pengalaman berpikir secara kreatif (think), menciptakan pengalaman pelanggan yang berhubungan dengan tubuh secara fisik, dengan perilaku dan gaya hidup serta dengan pengalaman-pengalaman sebagai hasil dari interaksi dengan orang lain (act), juga menciptakan pengalaman yang terhubung dengan keadaan sosial, gaya hidup, dan budaya yang dapat direfleksikan merek tersebut yang merupakan pengembangan dari sensations, feelings, cognitions dan actions (relate).

Customer Relationship Management (CRM) adalah strategi inti dalam bisnis yang mengintegrasikan proses-proses dan fungsi fungsi internal dengan semua jaringan eksternal untuk menciptakan serta mewujudkan nilai bagi para konsumen sasaran secara profitable (Kotler \& Keller, 2016). Manajemen hubungan pengguna jasa (customer relationship marketing) adalah kegiatan keseluruhan perusahaan untuk memperoleh dan mempertahankan pengguna jasa (Pertiwi Siregar et al., 2020). Customer Relationship Management (CRM) mengenali pengguna jasa sebagai inti dari bisnis dan bahwa keberhasilan perusahaan tergantung pada hubungan dengan pengguna jasa yang dikelola secara efektif.

Loyalitas pelanggan adalah kesediaan pelanggan untuk terus berlangganan pada sebuah perusahaan dalam jangka panjang, dengan membeli dan menggunakan barang dan jasanya secara berulang-ulang dan lebih baik lagi secara eksklusif, dan dengan suka rela merekomendasikan produk perusahaan tersebut kepada teman-teman dan rekanrekannya (Halim, 2021). Loyalitas 
p-ISSN : 2599-1418

e-ISSN : 2599-1426
Jurnal Pendidikan Ekonomi Undiksha

Vol. 13 No. 2 (2021) menunjukkan kondisi dari durasi waktu tertentu dan mensyaratkan bahwa tindakan pembelian terjadi tidak kurang dari dua kali (Hurriyati, 2010). Loyalitas akan belanjut hanya sepanjang pelanggan merasakan bahwa pelanggan menerima kualitas yang lebih baik dibandingkan dengan tawaran dari perusahaan lain (Prasetyo \& Yani, 2020).

Observasi yang dilakukan selaman penelitian menunjukkan bahwa dalam satu periode ini khususnya di masa pandemi covid yang mewabah jumlah tamu yang menggunakan jasa restaurant di Damarmas resort Kediri semakin mengalami naik turun jumlah tamu yang datang, diperlukan adanya suatu strategi pemasaran yang benar agar berdampak pada meningkatnya jumlah tamu yang menginap. Hasil dari pelaksanaan penelitian Experential Marketing dan Customer Relationship Management ini diharapkan akan berdampak pada tumbuhnya kepuasan pelanggan yang dapat mempertahankan tamu potensial yang loyal. Dalam penelitian ini, menunjukkan bahwa salah satu strategi bidang pemasaran yakni lewat Experential Marketing dan CRM (Customer Relationship Management) telah dijalankan oleh pihak manjemen Damarmas resort, sehingga dari hasil yang terlihat di lapangan yang telah dilakukan menampakkan adanya pengaruh positif terhadap Kepuasan Pelanggan. Namun untuk mempertahankan eksistensi Damarmas resort dalam persaingan bisnis penyedia jasa perhotelan di Kabupaten Kediri, disarankan untuk mengimplementasikan Experential Marketing dan CRM (Customer Relationship Management) dengan tetap konsisten dan selalu melakukan evaluasi secara berkala dan terus menerus guna menciptakan kepuasan pada diri pengguna jasa itu sendiri sekaligus dapat memperoleh dan mempertahankan pengguna jasa yang loyal.

Setelah dilakukan pra riset pada pengguna jasa damarmas resort terdapat beberapa alasan yang menjadi faktor adanya penelitian ini yaitu mengenai indikasi keluhan dari pengguna jasa seperti pelayanan yang kurang baik, misalnya terlalu lama dalam melayani antrian maupun pemberian pesanan produk sehingga terjadi penumpukan di antrian pengguna jasa, kemudian kurangnya informasi produk pada pengguna jasa sehingga pelangan bingung menentukan pilihan. Banyak juga pengguna jasa yang memberi ulasan positif seperti rasa yang enak, harganya terjangkau serta adanya promo yang dilakukan oleh Damarmas resort. Semenjak awal bulan Maret 2020, terjadi perubahan yang dirasakan masyarakat Indonesia pada kehidupan hariannya dikarenakan adanya epidemi virus corona atau COVID-19. Salah satu perubahannya berupa imbauan pemerintah agar masyarakat menjaga jarak dan tetap tinggal di rumah, dalam rangka usaha pencegahan penularan COVID-19, pemerintah mengimbau masyarakatnya untuk menjaga jarak dan tetap tinggal di rumah. Dengan adanya imbauan untuk menjaga jarak dan tinggal di rumah tentu saja memberi efek yang drastis pada berbagai sektor dalam kehidupan. Salah satu sektor yang terkena dampaknya adalah restaurant. Terfokus pada aktivitas operasional, Damarmas mengalami penurunan nilai penjualan dan jumlah transaksi yang mempengaruhi perputaran khas perusahaan dan adanya perubahan pola konsumsi masyarakat yang dikarekanan tekanan COVID 19.

\section{Hubungan Experiential Marketing dengan Loyalitas Pengguna Jasa}

Perusahaan jasa memandang pengguna jasa sebagai seseorang yang rasional dan emosional yang berfokus pada experiential marketing yang didapatkan saat menggunakan suatu produk atau jasa (Spotswood et al., 2021). Experiential marketing tersebut memberikan peranan penting dalam menentukan persepsi pelanggan terlebih pada kondisi pandemi seperti ini. Experiential marketing pelanggan menghasilkan banyak keluaran yang positif misalnya pelanggan yang mendapatkan pengalaman yang menyenangkan akan melakukan pembelian produk tersebut kembali dan merekomendasikan produk tersebut kepada teman dan keluarganya (Febrianti \& Keni, 2021).

Berdasarkan penelitian dari Soliha et al. (2021) loyalitas pengguna jasa Hotel dapat dipengaruhi dan dibentuk dari Experiential Marketing yang tercipta dalam persepsi pasca merasakan fasilitasfasilitasnya dalam memiih jasa. Temuan 
p-ISSN : 2599-1418

e-ISSN : 2599-1426

tersebut sejalan dengan penelitian dari Heryanto et al., (2021) bahwa experiential marketing berpengaruh positif dan signifikan terhadap loyalitas, artinya ketika pengguna jasa tersebut merasa puas, maka akan terjadi interaksi atau kepercayaan yang tumbuh dan terjaga antara pengguna jasa dan perusahaan.

$\mathrm{H} 1$ : Experinetial marketing berpengaruh terhadap loyalitas pengguna jasa Damarmas resort

Hubungan Customer Relationship Management dengan Loyalitas Pengguna Jasa

Salah satu syarat strategi bersaing perusahaan untuk mencapai keunggulan kompetitif berkelanjutan dalam bisnis adalah fokus pada pengguna jasa (Zamzam \& Jatmiko, 2019). Dalam memahami fokus pengguna jasa, perusahaan membutuhan informasi profil dari pengguna jasa mereka, kemudian keinginan dan kebutuhan yang dinginkan pengguna jasa, bagaimana cara memuaskan pengguna jasa mereka dan faktor-faktor yang terkait dengan pengguna jasa (Jatmiko, 2016). Customer relationship management (CRM) merupakan strategi tentang bagaimana mengoptimalkan profitabilitas melalui hubungan baik dengan pengguna jasa dan penciptaan kepuasan pengguna jasa (Kotler et al., 2017). Customer relationship management merupakan salah satu sarana untuk menjalin hubungan yang berkelanjutan antara perusahaan dengan para pemangku kebijakan dalam sebuah perusahaan. Saat ini banyak perusahaan yang memanfaatkan Customer relationship management untuk menjalin hubungan erat dengan pengguna jasa, caranya memanfaatkan Customer relationship management (Rangkuti, 2013).

Kajian teori di atas juga didukung oleh hasil penelitian dari (Jaelani, 2020) bahwa keberadaan customer relationship management memberikan kontribusi yang positif terhadap loyalitas pengguna jasa. Temuan ini juga didukung hasil dari (Eri Agustin, 2020) bahwa CRM berpengaruh secara parsial dan signifikan positif terhadap loyalitas pengguna jasa. Berbeda dengan argument dari Agustin et al., (2019) bahwa customer relationship management tidak memiliki pengaruh yang nyata terhadap
Jurnal Pendidikan Ekonomi Undiksha

Vol. 13 No. 2 (2021)

loyalitas pengguna jasa. kajian gap diatas dapat disampaikan hipotesis:

$\mathrm{H} 2$ : customer relationship management berpengaruh terhadap loyalitas pengguna jasa Damarmas resort.

Hubungan Experiential Marketing dan Customer Relationship Management dengan Loyalitas Pengguna Jasa

Perusahaan akan mengetahui apa yang diharapkan dan diperlukan pengguna jasanya sehingga akan tercipta ikatan emosional yang mampu menciptakan hubungan bisnis yang erat dan terbuka serta komunikasi dua arah atau timbal balik di antara mereka (Jatmiko et al., 2018). Pengalaman yang menarik akan memunculkan kesetiaan pengguna jasa yang dapat dipertahankan agar tidak mudah berpindah ke lain produk dan merek, terlebih produk dan merek perusahaan pesaing (Vanhamme, 2016). Tentunya juga melibatkan para pengguna jasa tersebut dalam beberapa kegiatan perusahaan, agar hubungan baik antara pengguna jasa dan perusahaan tetap terjaga, sehingga kepercayaan pengguna jasa terhadap produk yang ditawarkan mudah diterima dan dinikmati (Suryati, 2019).

Hasil penelitian dari Jaelani, (2020) menyebutkan bahwa experiental marketing dan customer relationship management secara simultan mempengaruhi loyalitas. Hasil penelitian dari (Putri, 2019) juga menyatakan bahwa experiential marketing dan CRM meruka faktor yang penting dalam mempengaruhi loyalitas. Namun hal ini tidak sejalan dengan penelitian dari (Budiyanto \& Surya, 2019) yang menyebutkan experiential marketing berpengaruh negatif terhadap loyalitas konsumen. Hasil penelitian lain juga menyebutkan bahwa customer relationship tidak berpengaruh signifikan terhadap loyalitas (Agustin et al., 2019). Mengacu pada gap riset diatas maka:

$\mathrm{H} 1$ : Experiential Marketing dan Customer Relationship Management dengan Loyalitas Pengguna Jasa Damarmas resort.

\section{METODE}

Jenis penelitian yang akan digunakan dalam proses penelitian ini adalah pendekatan kuantitatif, dengan 
p-ISSN : 2599-1418

e-ISSN : 2599-1426

menggunakan angka yang bersumber pada data distribusi frekuensi jawaban responden dan data hasil analisis statistika (Sugiyono, 2018). Teknik pengumpulan data pada penelitian ini menggunakan kuesioner dengan cara memberi seperangkat pertanyaan dan pernyataan tertulis kepada responden untuk dijawab (Siregar, 2014). Dalam penelitian ini tanggapan atau jawaban dari responden diukur menggunakan skala likert. Dalam proses penelitian ini, lokasi yang akan menjadi tempat penelitian adalah Damarmas resort Desa Ngancar Kabupaten Kediri. Jumlah sampel yang digunakan dalam penelitian ini sebanyak 89 pengunjung atau pengguna jasa hal ini didasari pada jumlah pengguna jasa yang tidak bisa dihitung atau diukur dalam fase penelitian, dengan teknik pengambilan sampel yang digunakan oleh peneliti adalah Accidental Sampling, adalah teknik pengambilan sampel yang dilakukan tanpa perencanaan atau dengan suatu kebetulan untuk mendapatkan jumlah anggota sampel (Wiratna, 2014). Alasan pengambilan sampel ini adalah hanya dibatasi pada jumlah pengguna jasa yang kebetulan ditemui pada saat penelitian dilakukan, selain itu pertimbangan periode penelitian juga mendasari pengambilan sampel dengan aksidental.

Metode dan teknik analisis data dalam penelitian ini menggunakan uji validitas dan reliabilitas untuk mengukur kevalidan instrument penelitian, setelah itu melakukan uji asumsi klasik untuk hasil data sebaran kuisioner hingga menunjukkan kenormlan data dan keabsahan data tersebut (Sirilius Seran, 2020). Teknik analisis data menggunakan analisa regresi linear berganda, kemudian dilakukan pengujian hipotesis uji t. Kriteria pengujian hipotesis tersebut dengan mengacu pada hasil nilai signifikan hitung, apabila nilai signifikan $t<$ 0,05 maka variabel bebas berpengaruh terhadap variabel terikat, begitu pula sebaliknya (Ghozali, 2013). Uji F juga digunakan sebagai langkah analisis pengaruh kedua variabel secara simultan terhadap variabel terikat (Santoso, 2019). Kemudian peneliti juga menggunakan dan melakukan uji koefisien determinan (R2) untuk mengetahui prosentase pengaruh variabel prediktor terhadap variabel
Jurnal Pendidikan Ekonomi Undiksha

Vol. 13 No. 2 (2021)

dependen (Rochaety et al., 2019), semua uji diatas dikerjakan dengan software SPSS for Windows 25.0.

\section{HASIL DAN PEMBAHASAN}

Berdasarkan hasil pengujian data melalui SPSS for windows, diperoleh ringkasan output hasil perhitungan secara rinci sebagai berikut :

Tabel 1. Hasil output dan Perhitungan SPSS Mengenai Analisis Regresi Regresi Berganda

\begin{tabular}{|c|c|c|c|}
\hline Variabel & $\begin{array}{l}\text { Koefisien } \\
\text { Regresi }\end{array}$ & $\mathbf{T}_{\text {hitung }}$ & Sig. $t$ \\
\hline $\begin{array}{l}\text { Experential } \\
\text { Marketing }\end{array}$ & 0.661 & 8.409 & 0.000 \\
\hline $\begin{array}{l}\text { Customer } \\
\text { Relationship } \\
\text { Management }\end{array}$ & 0.422 & 4.288 & 0.004 \\
\hline $\begin{array}{c}\text { Konstanta (a) } \\
\mathrm{R}\end{array}$ & & & $\begin{array}{c}10.284 \\
0,672\end{array}$ \\
\hline $\begin{array}{l}\text { R Square } \\
\left(\mathrm{R}^{2}\right)\end{array}$ & & & 0,452 \\
\hline $\begin{array}{l}F_{\text {hitung }} \\
\text { Sig. } F_{\text {hitung }}\end{array}$ & & & $\begin{array}{c}15.443 \\
0.000\end{array}$ \\
\hline
\end{tabular}

Sumber: Hasil Output SPSS Diolah, 2021.

Berdasarkan perhitungan di atas maka dapat digambarkan strukturisasi hubungan antara experiential marketing dan customer relationship management terhadap loyalitas pengguna jasa seperti pada gambar berikut

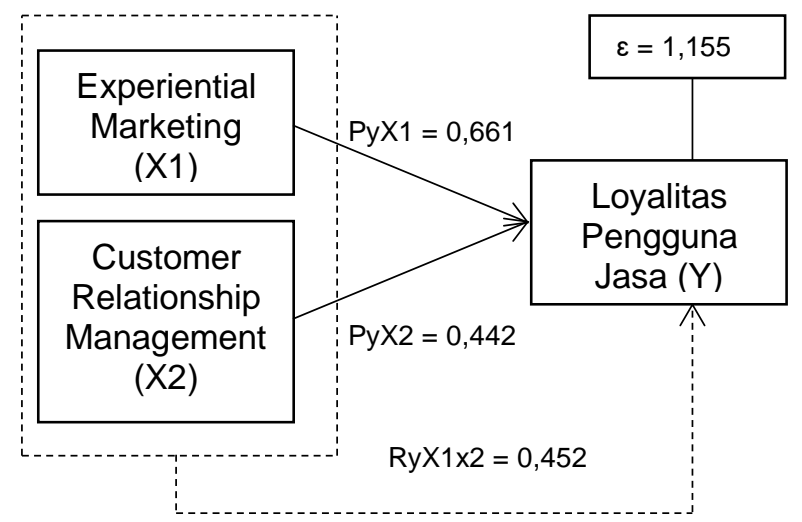


p-ISSN : 2599-1418

e-ISSN : 2599-1426
Jurnal Pendidikan Ekonomi Undiksha

Vol. 13 No. 2 (2021)
Gambar 1. Struktur Hubungan Antara

Experiential Marketing dan CRM terhadap Loyalitas

Merujuk pada hasil perhitungan yang telah dilakukan pada tabel 1 diatas, maka dapat dijelaskan terperinci bahwa persamaan regresi dalam penelitian ini sebagai berikut :

$Y=10,284+0,661 X 1+0,442 X 2$

Persamaan di atas menggambarkan bahwa nilai konstanta (a) sebesar 4,606 artinya apabila experiential marketing (X1), dan Customer Relationship Management (X2) dalam kondisi tetap atau konstan maka besarnya loyalitas adalah 10,284. Nilai koefisen regresi experiential marketing (X1) sebesar 0,661 dapat diartikan setiap ada penambahan strategi experiential marketing akan berpengaruh positif dan menambah peningkatan loyalitas sebesar 0,661 atau $66,1 \%$. Nilai koefisien regresi Customer Relationship Management (X2) sebesar 0,422 artinya setiap ada penambahan variabel CRM maka loyalitas pengguna jasa akan meningkat sebesar 0,422 atau 42,2\%.

Nilai koefisien determinasi ditunjukkan oleh besarnya nilai Rsquare $\left(R^{2}\right)$ sebesar 0,452 hal ini berarti bahwa $45,2 \%$ variabel loyalitas dapat dipengaruhi oleh variasi dari variabel independen antara experiential marketing dan CRM, sedangkan sisanya dijelaskan oleh sebab-sebab diluar variabel penelitian. Hubungan antara experiential marketing dan customer relationship management Koefisien korelasi $(\mathrm{R})$ di atas sebesar 0.672 ini artinya bahwa ada hubungan yang kuat antara variabel independen dengan variabel dependen, karena mendekati angka 1.

Berdasarkan hasil perhitungan analisis regresi linear berganda diperoleh pengaruh masing-masing variabel bebas terhadap variabel independen dengan melihat nilai $t$ hitung dan signifikasinya. Pengambilan keputusan dalam penelitian ini, apabila thitung $>t_{\text {tabel }}$ atau nilai signifikansi < nilai $\alpha(0.05)$ maka variabel tersebut dinyatakan positif mempengaruhi variabel dependennya. Secara parsial experiential marketing (X1) mempunyai nilai thitung sebesar 8.409 dan nilai signifikansi sebesar $0.000<0.05$, hal ini berarti bahwa experiential marketing (X1) berpengaruh positif dan signifikan terhadap loyalitas (Y). Customer Relationship Management (X2) mempunyai nilai thitung sebesar 4.288 dan nilai signifikansi sebesar $0.004<0.05$, hal ini berarti bahwa Customer Relationship Management (X2) berpengaruh positif dan signifikan terhadap loyalitas $(\mathrm{Y})$.

Melihat hasi analisis regresi di atas juga disampaikan gambaran hasil uji hipotesis secara simultan melalui uji $F$. Kriteria pengujian ini adalah apabila nilai siginifikan $\mathrm{F}$ berada $<0,05$ maka Ho ditolak dan $\mathrm{Ha}$ diterima artinya variabel bebas secara simultan berpengaruh terhadap variabel dependen. Nilai $F_{\text {hitung }}$ sebesar 15,443 dengan probabilitas signifikan sebesar 0.000 , nilai probabilitas lebih kecil dari 0.05 , maka regresi dapat digunakan untuk memprediksi bahwa variabel experiential marketing, customer relationship management secara simultan berpengaruh positif dan signifikan variabel loyalitas pengunjung di Damarmas Resort Desa Ngancar Kabupaten Kediri.

Pengaruh Experiential Marketing Terhadap Loyalitas Pengguna Jasa Pada Damarmas Resort Kediri di Masa Pandemi

Berdasarkan kajian hasil penelitian yang telah dilakukan bahwa experiential marketing (X1) berpengaruh positif dan signifikan terhadap loyaltas $(\mathrm{Y})$, hal ini berarti $\mathrm{H} 1$ diterima. Temuan ini menunjukkan bahwa tidak semua dimensi experiential marketing mampu menciptakan pengalaman bagi konsumen untuk mengunjungi Damarmas Resort Ngancar Kediri. Hasil temuan tersebut mengindikasikan bahwa masih perlunya pengelolaan strategi pemasaran khususnya dalam mempengaruhi psikologis konsumen diwilayah penanaman pengalaman yang menarik dalam merasakan jasa di Damarmas Resort terlebih pada masa pandemi berlangsung. Berdasarkan keterangan para responden mayoritas berargumen bahwa pengalaman itu lebih mengena dan berkesan ketika unsur desain Interior dan kesejukan ruangan selalu ditingkatkan, karena dapat menambah selera pengguna jasa resort tersebut, sehingga para pengguna jasa yang telah merasakan jasa di resort tersebut akan lebih leluasa dalam memberikan informasi 
p-ISSN : 2599-1418

e-ISSN : 2599-1426
Jurnal Pendidikan Ekonomi Undiksha

Vol. 13 No. 2 (2021) mengenai keberadaan resort ini kepada khalayak, khususnya di masa pandemi covid 19 ini sehingga secara tidak langsung dapat membantu promosi pihak manajemen terkait pengelolaan usaha yang akan lebih dikenal orang banyak agar mampu bertahan dalam masalah keterpurukan penerimaan dari sektor tata kelola usaha jasa di era pandemi ini.

Temuan penelitian ini didukung oleh dengan hasil penelitian Yeh et al., (2019) bahwa experiential marketing didesain untuk bisa menciptakan pengalaman layanan yang tidak terlupakan. Hasil penelitian ini juga sesuai dengan kajian penelitian dari Heryanto et al., (2021) dan Soliha et al., (2021) yang menjelaskan bahwa experience konsumen mampu menumbuhkan dan mempengaruhi loyalitas pelanggan. Akan tetapi temuan penelitian ini berbeda dengan penelitian Le et al., (2019) menjelaskan bahwa kemampuan dari pemasaran yang berorientasi pada pengalaman tidak mempengaruhi loyalitas bagi pengguna jasa. Hasil ini juga diperkuat oleh Yeh et al., (2019) yang mengungkapkan bahwa experiential marketing belum mampu mempengaruhi loyalitas secara langsung.

Pengaruh Customer Relationship Management Terhadap Loyalitas Pengguna Jasa Pada Damarmas Resort Kediri di Masa Pandemi.

Hasil penelitian menunjukkan bahwa Customer Relationship Management (X2) berpengaruh positif dan signifikan terhadap loyalitas $(\mathrm{Y})$, hal ini berarti $\mathrm{H} 2$ diterima. Temuan penelitian ini mengindikasikan bahwa semakin efektif Customer Relationship Management dimasa pandemi ini diterapkan maka akan menghasilkan loyalitas pengguna jasa yang meningkat signifikan. Pandemi covid 19 ini memang menyerang segala aspek khususnya seluruh sektor perekonomian, maka dari itu para pelaku usaha atau pimpinan memerlukan strategi khusus dalam usaha mempertahankan keberlangsungan kegiatan operasionalnya salah satunya menjaga hubungan baik dengan para pengguna jasanya. Salah satu strategi pada masa pandemi covid 19 yang tetap dirasakan oleh para pengguna jasa di Damarmas Resort adalah kesigapan para pengelola usaha tersebut dengan merespon kebutuhan pengguna jasa secara cepat. Hal lain yang menjadi persepsi pengguna jasa dalam konteks menjaga hubungan baik adalah proses pelayanan pada saat pengguna jasa memesan resort dilakukan secara tidak berbelit-belit. Perlakuan baik kepada para penguna jasa ini dapat menjadi pola keterikatan antara penyedia jasa dengan penikmat jasa, sehingga loyalitas tetap terjaga bukan tidak mungkin jumlah penerimaan pengunjung resort ini mampu dipertahankan di masa pandemi covid 19.

Hasil peneltian ini sesuai dengan pendapat Jaelani, (2020) bahwa customer relationship mempengaruhi loyalitas secara positif dan signifikan, hal ini juga dipertegas oleh pendapat (Eri Agustin, 2020) dengan mengatakan bahwa loyalitas dibentuk oleh strategi CRM yang baik. Pernyataan bahwa dalam tahap implementasi CRM, perusahaan dapat meningkatkan keuntungan yang diperoleh dari pengguna jasa yang sudah ada dengan mendorong terciptanya produk atau jasa komplemen dan penjualan produk atau jasa yang lebih baik dari produk atau jasa yang dimiliki oleh pengguna jasa (Kotler, Philip \& Amstrong, 2016). Hasil Penelitian ini tidak sesuai dengan pendapat dari (Pertiwi Siregar et al., 2020) bahwa strategi Customer Relationship Management (CRM) tidak mampu memberikan pengaruh secara signifikan terhadap loyalitas. Hal ini juga berbeda dengan Agustin et al., (2019) juga menerangkan bahwa CRM berpengaruh negatif terhadap loyalitas pelanggan.

Pengaruh Experiential Marketing dan Customer Relationship Management Terhadap Loyalitas Pengguna Jasa Pada Damarmas Resort Kediri di Masa Pandemi

Berdasarkan hasil penelitian disampaikan bahwa experiential marketing dan customer relationship management berpengaruh secara simultan terhadap loyalitas pengguna jasa di Damarmas Resort. Hasil menunjukkan bahwa adanya hubungan yang sangat tidak bisa terpisahkan antara fungsi dari experiential marketing dan customer relationship management terhadap loyalitas pengguna jasa inilah yang menjadikan experiential marketing dan customer relationship 
p-ISSN : 2599-1418

e-ISSN : 2599-1426

management sebagai salah satu strategi perusahaan yang sangat diperhatikan oleh perusahaan (Batat, 2019). Dampak dari adanya strategi perusahaan inilah yang dapat membuat perusahaan menjadi penguasa pasar. Ketika strategi CRM perusahaan dilakukan secara maksimal, maka akan muncul pengaruh yang signifikan antara hubungan pengguna jasa dan perusahaan. Kepuasan merupakan kunci utama dari munculnya keloyalitasan pengguna jasa terhadap perusahaan (Suryati, 2019).

Hasil ini mendukung penelitian yang dilakukan oleh Nirawati et al., (2020) dan Jaelani (2020) serta Putri (2019) yang menyatakan bahwa variabel experiential marketing dan customer relationship management berpengaruh signifikan terhadap variabel Loyalitas Pengguna jasa. Selain itu penelitian ini tidak sejalan dengan penelitian sebelumnya yang dilakukan oleh Nurhayati, (2020) dan Agustin et al., (2019) yang menyatakan bahwa varibel experiential marketing dan customer relationship management secara bersama berpengaruh negatif terhadap Loyalitas Pengguna jasa di Damarmas Resort Ngancar Kediri.

\section{SIMPULAN DAN SARAN}

Berdasarkan atas hasil analisis data dan pembahasan yang telah dilakukan, maka dapat disampaikan kesimpulan dari penelitian ini bahwa experiential marketing dan Customer Relationship Management secara parsial berpengaruh positif dan signifikan terhadap loyalitas. Secara simultan hasil penelitian juga menunjukkan bahwa keberadaan variabel experiential marketing dan Customer Relationship Management berpengaruh positif dan signifikan terhadap. Berdasarkan kesimpulan yang disampaikan tersebut hendaknya pihak Damarmas Resort Kediri perlu mempertimbangkan untuk sesekali memberlakukan sistem paket resto dan paket penginapan pada saat musim pandemi covid 19 dengan tetap memperhatikan protocol kesehatan dan kebijakan pemerintah pusat atau daerah, misalnya pemesanan sebesar jumlah yang telah ditentukan akan mendapatkan cash back pemesanan, diskon, atau program lainnya yang dapat meningkatkan
Jurnal Pendidikan Ekonomi Undiksha

Vol. 13 No. 2 (2021)

penerimaan finansial perusahaan khususnya pada era pandemi.

\section{DAFTAR PUSTAKA}

Agus Najibul Zamzam, N., \& Jatmiko, U. (2019). Persepsi Jamaah Mengenai Fasilitas dan Biaya dalam Memilih Jasa Umroh. Jurnal IImu Manajemen Advantage, $3(2)$. https://doi.org/10.30741/adv.v3i2.470

Agustin, W., Sofyaun, A., \& Indriawati, P. (2019). Pengaruh Customer Relationship Management (CRM) Terhadap Loyalitas Konsumen Astra Motor MT Haryono Di Balikpapan. Jurnal Edueco, 2(1). https://doi.org/10.36277/edueco.v2i1.3 2

Ayu Fandani Eri Agustin, A. M. (2020). Pengaruh Customer Relationship Management Terhadap Kepuasan Konsumen. E-Proceeding of Applied Science: Vol.6, No.2 Agustus 2020, 6.

Batat, W. (2019). Experiential marketing: Consumer behavior, customer experience and the 7Es. In Experiential Marketing: Consumer Behavior, Customer Experience and The 7Es. https://doi.org/10.4324/978131523220 1

Budiyanto, G. A., \& Surya, D. (2019). Pengaruh Kualitas Pelayanan Dan Customer Relationship Management Terhadap Loyalitas Pelanggan Dengan Kepuasan Pelanggan Sebagai Variabel Intervening. Jurnal Riset Bisnis Dan Manajemen Tirtayasa, 3(2).

Chang, W. J. (2021). Experiential marketing, brand image and brand loyalty: a case study of Starbucks. British Food Journal, 123(1). https://doi.org/10.1108/BFJ-01-20200014

Febrianti, I. N., \& Keni, K. (2021). Pengaruh Experiential Marketing dan Service Quality terhadap Customer Loyalty: Customer Satisfaction sebagai Variabel Mediasi. Jurnal Manajemen Bisnis Dan Kewirausahaan, $5(1)$. https://doi.org/10.24912/jmbk.v5i1.104 00

Ghozali, I. (2013). Aplikasi Analisis Multivariate Dengan Program IBM SPSS 21Update PLS Regresi. 
p-ISSN : 2599-1418

e-ISSN : 2599-1426

Semarang: Badan Penerbit Universitas Diponegoro.

Halim, fitria. (2021). Manajemen Pemasaran Jasa - Google Books. In Yayasan Kita Menulis.

Heryanto, H., Hidayati, T., \& Wahyuni, S. (2021). Pengaruh Experiential Marketing dan Kualitas Pelayanan terhadap Kepuasan Konsumen dan Word of Mouth. Syntax Literate ; Jurnal IImiah Indonesia, 6(1). https://doi.org/10.36418/syntaxliterate.v6i1.2277

Hurriyati, R. (2010). Bauran Pemasaran Dan Loyalitas Pelanggan. In Pendidikan Manajemen Bisnis.

Jaelani, E. (2020). Pengaruh Customer Relationship Management Terhadap Loyalitas Nasabah Bank "X" Di Bandung. JSMA (Jurnal Sains Manajemen Dan Akuntansi), 12(1). https://doi.org/10.37151/jsma.v12i1.46

Jatmiko, U. (2016). Pengaruh Lingkungan Bisnis Dan Orientasi Kewirausahaan Terhadap Peningkatan Kinerja Pelaku UKM Pada Tahap Start-Up Di Desa Paron Kecamatan Ngasem Kabupaten Kediri. Jurnal Manajemen \& Kewirausahaan, 1(3), 235-246. https://ejournal.uniska-

kediri.ac.id/index.php/ManajemenKewi rausahaan/article/view/247

Jatmiko, U., Srikalimah, S., \& Zamzam, N. A. N. (2018). Analisis Reaksi Pelaku UMKM Tahap Start Up Dalam Membandingkan Modal Kerja dan Pendapatan Usaha Sebelum dan Sesudah Adanya Inovasi Produk MAMIN di Wilayah Kediri dan Tulungagung. Jurnal IImu Manajemen Advantage, $2(2)$. https://doi.org/10.30741/adv.v2i02.359

Kotler, Philip \& Amstrong, G. (2016). Principles of marketing (11 ed.). In New York: Pearson International.

Kotler \& Keller. (2016). Kotler \& Keller Marketing Management. In Boletin cultural e informativo - Consejo General de Colegios Medicos de España (Vol. 22).

Kotler, P., Bowen, J. T., Makens, J. C., \& Baloglu, S. (2017). Marketing for hospitality and tourism. In Always learning.
Jurnal Pendidikan Ekonomi Undiksha

Vol. 13 No. 2 (2021)

Le, D., Scott, N., \& Lohmann, G. (2019). Applying experiential marketing in selling tourism dreams. Journal of Travel and Tourism Marketing, 36(2). https://doi.org/10.1080/10548408.2018 .1526158

Nirawati, L., Pratiwi, A. D., Mutiahana, A., \& Afida, E. A. (2020). Pengaruh Kepercayaan Konsumen dan Pengalaman Pelanggan (Custumer Experience) Terhadap Loyalitas Pelanggan pada Aplikasi Shopee. Jurnal Syntax Transformation, 1(9).

Nurhayati, S. (2020). Pengaruh Brand Trust, Brand Experience Dan Kepuasan Pelanggan Terhadap Loyalitas Pelanggan. Jurnal.Amaypk.Ac.Id, VII(2).

Pertiwi Siregar, D. N., Cahyani, W., \& Chaniago, A. U. (2020). Pengaruh Customer Relationship Management (Crm) Terhadap Loyalitas Pengguna Irian Card (I-Card) Pada Irian Dept Store \& Supermarket Medan Marelan. Jurnal SAINTIKOM (Jurnal Sains Manajemen Informatika Dan Komputer), 19(1). https://doi.org/10.53513/jis.v19i1.221

Prasetyo, I., \& Yani, T. E. (2020). Meraih Loyalitas Pelanggan Dengan Etika Komunikasi Sales Dan Customer Relationship Management. Jurnal Ilmiah Manajemen "E MO R," 4(1). https://doi.org/10.32529/jim.v4i1.478

Putri, sindy asrika. (2019). Pengaruh customer relationship management terhadap loyalitas pelanggan dengan kepuasan pelanggan sebagai variabel intervening di hotel islami Aceh House. Jurnal Riset Mahasiswa Manajemen.

Rangkuti, F. (2013). Customer Service Satisfaction \& Call Center Berdasarkan ISO 9001. In Jakarta: Gramedia Pustaka Utama.

Rochaety, E., Tresnati, R., \& Latief, A. M. (2019). Metodologi penelitian bisnis dengan aplikasi SPSS. In Jakarta: Mitra Wacana Media.

Santoso, S. (2019). Statistik Parametrik. Statmat: Jurnal Statistika Dan Matematika, May.

Siregar, I. S. (2014). Metode Penelitian Kuantitatif Dilengkapi Dengan Perhitungan Manual dan SPSS. 
p-ISSN : 2599-1418

e-ISSN : 2599-1426

Jakarta: PT. Fajar Interpratama Mandiri.

Sirilius Seran. (2020). Metodologi Penelitian Ekonomi Dan Sosial. In Metodologi Penelitian Ekonomi Dan Sosial.

Smith, K., \& Hanover, D. (2016). Experiential Marketing: Secrets, Strategies, and Success Stories from the Worldâs Greatest Brands. In Experiential Marketing: Secrets, Strategies, and Success Stories from the Worldâs Greatest Brands. https://doi.org/10.1002/978111917668 8

Soliha, E., Aquinia, A., Hayuningtias, K. A., \& Ramadhan, K. R. (2021). The Influence of Experiential Marketing and Location on Customer Loyalty. Journal of Asian Finance, Economics and Business, $8(3)$. https://doi.org/10.13106/jafeb.2021.vol 8.no3.1327

Spotswood, F., Wiltshire, G., Spear, S., \& Makris, A. (2021). Disrupting social marketing through a practice-oriented approach. RAUSP Management Journal, $56(3)$.
Jurnal Pendidikan Ekonomi Undiksha

Vol. 13 No. 2 (2021)

https://doi.org/10.1108/RAUSP-102020-0231

Sugiyono. (2018). Metode Peneiltian Kuantitatif, Kualitatif dan R\&D. In Alfabeta Bandung.

Suryati, L. (2019). Manajemen Pemasaran Suatu Strategi Dalam Meningkatkan Loyalitas Pelanggan. In Hakikat Pemasaran.

Vanhamme, J. (2016). Memorable Customer Experiences. In Memorable Customer Experiences.

https://doi.org/10.4324/978131559482 8

Wiratna, S. (2014). Metodologi penelitian Lengkap, Praktis dan Mudah Dipahami. Pt.Pustaka Baru, 1(Metodologi Penelitian).

Yeh, T. M., Chen, S. H., \& Chen, T. F. (2019). The relationships among experiential marketing, service innovation, and customer satisfaction- $A$ case study of tourism factories in Taiwan. Sustainability (Switzerland), 11(4).

https://doi.org/10.3390/su11041041 